\title{
PERKEMBANGAN KOGNITIF MELALUI MEDIA KUBUS PUTAR DADU ANGKA
}

\author{
Indaria Tri Hariyani ${ }^{1}$ \\ STKIP Bina Insan Mandiri Surabaya \\ indahariyani442@gmail.com \\ Suparti \\ STKIP Bina Insan Mandiri Surabaya \\ supartirifiyanto@gmail.com
}

\begin{abstract}
ABSTRAK
Berdasarkan observasi di TK Syeich Abu Bakar Surabaya kelompok A ada beberapa masalah yang berkaitan dengan kegiatan belajar mengajar pada Kelompok A. Anak-anak pada umumnya belum bisa mengenal angka, masih rendah pada arahan atau bimbingan yang diberikan Guru. Tujuan penelitian ini adalah untuk mengarahkan anak - anak agar dapat bermain media kubus putar dadu angka dan mengenalkan angka 1- 10 yang ada disisisisi kubus putar tersebut, dengan bahasa yang sopan saat bermain. Metode pengumpulan data yang digunakan dalam penelitian ini adalah observasi, wawancara dan dokumentasi. Dengan Subjek penelitian adalah 15 orang siswa kelompok di TK Syeich Abu Bakar Surabaya. Teknis analisis data menggunakan analisis deskriptif kualitatif. Hasil penelitian menunjukkan bahwa proses penerapan perkembangan kognitif anak usia dini melalui media kubus putar dadu angka untuk mengenal bilangan di kelompok A TK Syeich Abu Bakar Surabaya bahwa dengan adanya media kubus putar dadu angka ini anak-anak sudah mulai bisa mengenal angka 1 - 10 membuat anak-anak lebih mudah dan bisa mengenal angka. Pengenalan angka dari sejak dini anak-anak sudah sangat totalitas dan antusias dengan terciptanya APE berupa media kubus putar dadu angka ini yang membuat kegiatan pembelajaran berjalan dengan baik.
\end{abstract}

Kata Kunci: Perkembangan Kognitif, Media Kubus Putar Dadu Angka

Received 03- 11- 2021; Received in revised form 14-12-2021; Accepted 31-12-2021

\begin{abstract}
Based on observations at the Syich Abu Bakar Kindergarten in Surabaya, group A, there are several problem related to teaching and learning activities in Group A. In general, children cannot recognize numbers, they are still low on the direction or guidance given by the teacher. The purpose of this study is to direct children to be able to play the media of the dice cube and introduce the numbers $1-10$ on the sides of the rotating cube, with polite language when playing. Data collection method used in this study were observation, interviews and documentation. The research subjects were 15 group students at Syeich Abu Bakar Kindergarten Surabaya. Technical analysis of data using descriptive qualitative analysis. The results showed that the process of applying the cognitive development of early childhood through the dice cube media to recognize numbers in group A of TK Syeich Abu Bakar Surabaya that with the dice cube media the children have started to recognize the numbers 1 - 10 making childrens are easier and can recognize numbers. Recognizing
\end{abstract}


numbers from an early age, children are very total and enthusiastic about the creation of $A P E$ in the form of a dice cube media that makes learning activities run well.

Keywords: Cognitive Development, Media Cube Dice Number

\section{A. PENDAHULUAN}

Anak usia dini adalah anak yang berusia $0-6$ tahun. Seperti yang tertuang pada Undang - Undang Sistem Pendidikan Nasional tahun 2003 pasal 18 ayat 1 dan Ayat 1 Pasal 1 A. Bahwasannya PAUD (Pendidikan Anak Usia Dini) dilaksanakan dari sejak lahir sampai umur enam tahun yang melalui jalur Pendidikan Formal berbentuk dalam sebuah lembaga TK, lalu lanjut ke jenjang SD (Sekolah Dasar).

PAUD (Pendidikan Anak Usia Dini) diartikan untuk anak berusia 0-6 tahun (golden age) sebab perkembangan anak yang berusia ini berkembang sangat baik dalam masa perkembangannya, baik secara psikis maupun fisik. Masa peka dalam perkembangannya adalah anak berusia 6 tahun. Masa pematangan fungsi-fungsi fisik dan pikir yang siap merespon stimulasi lingkungan dan mengasimilasi dan menginternalisasi ke dalam pribadinya adalah arti dari masa peka. Masa ini merupakan masa awal pengembangan kemampuan, nilai moral agama, kognitif, bahasa, sosial emosional, fisik motorik, konsep diri, kemandirian dan disiplin.

Menurut Fauziddin (2016.) berpendapat bahwa pendidikan anak usia dini ialah anak usia 0-6 tahun, pendidikan anak usia dini memiliki peranan yang sangat penting untuk mengembangkan kepribadian anak serta mempersiapkan anak untuk memasuki jenjang pendidikan yang lebih lanjut. Menurut Dwi Yulianti (2010.) berpendapat bahwa anak usia dini adalah anak yang berada dalam usia 0-8 tahun. Anak usia dini adalah anak yang berusia antara 3-6 tahun. Menurut Augusta (2012.) mengatakan hakikat anak usia dini ialah individu yang unik dimana ia memiliki pola pertumbuhan dan perkembangan dalam 5 aspek perkembangan anak yaitu fisik, motorik, bahasa, kognitif, sosial dan emosional. Menurut Depdiknas (2007.) Taman kanak-kanak merupakan lembaga pendidikan formal sebelum memasuki sekolah dasar. Lembaga ini sangat strategis dan penting dalam menyediakan pendidikan bagi anak usia 4-6 tahun. Analisa ini merupakan golden age "masa peka" yang hanya datang sekali. Masa peka ialah masa yang menurut perkembangan anak dikembangkan secara optimal. Untuk memenuhi kebutuhan berekspresi dengan berbagai cara dan media kreatif (alat untuk berkreasi) seperti kegiatan-kegiatan dengan berbagi alat yang digunakan yaitu cat air, buku gambar, spidol .kertas origami, pendidikan TK telah memberi kesempatan sepenuhnya.

TK Syeich Abu Bakar Surabaya merupakan salah satu sekolah formal yang mendidik anak usia dini dengan kegiatan belajar mengajar, dan siswa taman kanakkanak pada Kelompok A berada pada tahap pra operasional. Anak-anak pada umumnya belum bisa mengenal angka, masih rendah pada arahan atau bimbingan yang diberikan guru. Hampir sebagian besar anak di TK Syeich Abu Bakar 
J-SANAK: Jurnal Kajian Anak (p-ISSN: 2686-5343 |e-ISSN: 2715-7989)

Vol. (3)(01), (Juli-Desember)(2021), (Halaman)(1-11)

DOI: https://doi.org/10.24127/j-sanak.v3i01.1574

Surabaya, masih belum bisa mengenal angka 1-10, yang harus dilakukan guru untuk meningkatkan kognitifnya dalam mengenal bilangan 1-10, yaitu dengan mengajak anak-anak untuk belajar sambil bermain dengan bermain kubus putar dadu.

Media yang terbuat dari kertas lipat yang dibentuk menjadi kubus lalu diberi angka sisi- sisinya ada 4 angka yang akan ditempel disisi kubus yang berbentuk seperti dadu, kubus dimasukan kedalam kawat dan ditancapkan pada lubang kayu sehingga kubus itu bisa berputar. Kubus tersebut diberi angka 1-10, dari angka 110 semua kubus itu bisa diputarkan dengan 4 sisi terlihat angkanya itu yang dimaksud dengan media kubus putar dadu.

Kemampuan atau potensi intelektual seseorang dalam berpikir, mengetahui, dan memecahkan masalah. Dengan demikian kognitif berkaitan dengan persoalan yang menyangkut kemampuan untuk mengembangkan kemampuan otak adalah pengertian dari kognitif. Sehingga kognitif berkaitan dengan persoalan yang berhubungan dengan kemampuan untuk mengembangkan kemampuan otak.

Fitria Uly Khusnaya (2019.) untuk mendapatkan stimulasi yang tepat, maka setiap anak mampu mencapai tahap perkembangan kognitifnya. Dalam tahap ini perlu pembiasaan setiap hari yang dilakukan di sekolah dalam waktu pembelajaran, anak-anak perlu rangsangan untuk mengembangkan kemampuan kognitifnya. Dengan pembiasaan ini dan dengan media pembelajaran sambil bermain, diharapkan dikenalkan konsep angka, sehingga anak menjadi bisa dan paham tentang angka. Dan anak tidak hanya menonton, tidak hanya melihat dan mendengar. Guru harus bisa memasukkan unsur kretifnya dalam permainan tersebut sehingga secara tidak sadar anak telah belajar mengenal angka dengan berhitung dan berbagai hal.

Menurut Isjoni (2011.) Model pembelajaran anak usia dini. Bermain merupakan bentuk kegiatan yang memberikan kepuasan pada diri anak dan bersifat tidak serius, lentur dan bahan bermain. Bermain ialah aktivitas yang membuat hati seorang anak menjadi senang dan nyaman serta bersemangat. Pada proses pembelajaran seorang guru harus bisa memilih metode pembelajaran yang tepat untuk mengajar peserta didiknya, sehingga anak-anak merasa senang, tetapi sebaliknya apabila seorang guru tidak kreatif maka pembelajaran tidak akan berjalan dengan lancar. Semuanya dikarenakan terbatasnya dan kurang menarik Alat Permainan Edukatif (APE) yang digunakan dalam penggunaan pembelajaran kurang bervariasi. Sehingga anak-anak menjadi bosan karena pembelajaran yang selalu monoton saja hanya menggunakan Lembar Kreativitas Anak (LKA) saja dan model pembelajaran klasikal.

Dari paparan diatas maka peneliti melakukan observasi tentang Penerapan Perkembangan Kognitif Anak Usia Dini Melalui Media Kubus Putar Dadu Mengenal Angka di Kelompok A TK Syeich Abu Bakar Surabaya. Dengan 
mengenalkan bilangan 1-10 pada anak Kelompok A memakai media kubus putar dadu. Sebelum bermain media kubus putar dadu ini peneliti memperkanalkan cara menggunakannya, lalu anak-anak belajar mencobanya sehingga anak -anak merasa senang dan mudah karena bisa belajar sambil bermain. Dengan pembelajaran ini anak-anak bisa memecahkan masalahnya dan bisa berhitung bilangan 1-10.

Dari masalah yang dihadapi pada anak kelompok di TK Syeich Abu Bakar Surabaya Kelurahan Kedurus Kecamatan Karang pilang, maka peneliti mempunyai keinginan supaya dapat meningkatkan kamampuan kognitif dalam mengenal angka. Peneliti akhirnya memilih suatu kegiatan yang mampu meningkatkan kemampuan mengenal angka yakni melalui kegiatan bermain kubus putar angka. Melihat paparan yang ada di atas, maka peneliti mengambil judul " Perkembangan Kognitif Melalui Media Kubus Putar Dadu Angka Pada Anak Kelompok A Tk Syeich Abu Bakar Surabaya".

\section{B. METODOLOGI}

Metode penelitian yang digunakan dalam penelitian ini adalah metode penelitian kualitatif. Menurut Sugiono (2014.) metode penelitian adalah merupakan sesuatu cara ilmiah yang dipergunakan oleh para peneliti untuk memperoleh atau mengumpulkan data supaya tujuan tertentu. Suatu metode penelitian seharusnya dilakukan secara sistematis agar dapat mengetahui jawaban yang paling tepat agar semua rumusan masalah yang ada didalam penelitian, yang digunakan oleh peneliti saat ini adalah metode kualitatif.

Metode penelitian kualitatif ialah sebuah metode pendekatan penelitian yang menggunakan situasi sosialnya dengan memaparkan kenyataan yang benar berdasarkan kata-kata pengumpulan data dan analisis data yang bisa dipercaya. Metode kualitatif menurut Sugiono (2014.) kualitatif merupakan suatu penelitian yang berlandaskan pada positivism filsafat buat meneliti objek secara alamiah. Metode kualitatif dibantu oleh ketersediaan deskripsi. Kualitatif didorong oleh pemahaman subtansi dari suatu peristiwa. Maka dari itu, penelitian kualitatif bukan hanya untuk memenuhi keinginan si peneliti untuk mendapatakan penjelasan atau gambaran, tapi bisa juga untuk membantu mendapatkan penjelasan yang lebih dalam.

Metode pengumpulan data dalam penelitian ini menggunakan observasi, wawancara dan dokumentasi. Maka penerapan perkembangan kognitif anak usia dini melalui media kubus putar dadu angka untuk mengenal bilangan di kelompok A untuk mengembangkan ketrampilan kognitifnya dalam mengenl bilangan angka, yaitu dengan menggunakan media kubus putar dadu angka.

\section{Setting penelitian}

Setting Penelitian ini rencananya dilakukan pada bulan April 2021 di TK Syeich Abu bakar Kota Surabaya. Rencana Penelitian Observasi ini dilakukan di 
Semester Genap pada tahun pelajaran 2020/2021, ada waktu yang pasti yaitu satu bulan penelitian dilakukan.

\section{Subyek dan objek penelitian}

Subjek dari penelitian ini adalah Murid TK Syeich Abu Bakar Surabaya yang ada 15 anak. Ada Guru kelas TK A1. Pada Pembelajaran Online TK Syeich Abu Bakar Kota Surabaya meliputi TK A : Bu Suparti, Bu Nurlulu'ah dan TK B : Bu Ika, Bu Chusnul, Bu Novi. Sedangkan objek penelitian ini ialah tentang penerapan perkembangan kognitifnya melalui media kubus putar dadu angka untuk mengenal bilangan di kelompok A TK Syeich Abu Bakar.

\section{Teknik pengumpulan data}

Berfungsi paling utama yaitu untuk memperoleh data yang diperlukan dalam penelitian, maka peneliti menggunakan teknik pengumpulan data berupa wawancara, observasi dan dokumentasi. Teknik pengumpulan data peneliti ini menggunakan teknik Observasi, wawancara, dan dokumentasi.

\section{a. Observasi}

Observasi adalah teknik pengamatan dan pencatatan secarasistematik terhadap unsur- unsur penelitia,. Metode observasi menurut Afifuddin (2012.) Observasi yang dipergunakan untuk penelitian adalah observasi yang terstruktur yang dirancang secara sistematis, sehingga apa yang akan telah diamati, dimana tempatnya dan kapan waktunya. Maka observasi yang terstruktur dilakukan bila peneliti telah mengetahui dengan betul sesuai dengan variabel apa yang akan dilihat atau diamati. Data yang mengenai Penerapan Media Kubus Putar Untuk Meningkatkan Kemampuan Mengenal Angka 1-10 Pada Kelompok A TK Syeich Abu Bakar Surabaya adalah data tentang tempat tinggal informan dan keadaan lingkungannya.

\section{b. Metode wawancara}

Wawancara ini digunakan untuk mengetahui beberapa aspek-aspek secara mendalam yang ada pada penelitian. Teknik wawancara dilakukan dengan cara menggunakan panduan wawancara yang terstruktur yang rileks, supaya harapannya bisa mengarahkan pada kejujuran, pikiran subyek penelitian ketika memberikan informasinya dan perilaku. Data yang diperoleh dengan menggunakan metode wawancara siapa-siapa saja yang diwawancarai dan kapan pelaksanaannya wawancara tersebut dilakukan adalah data mengenai Penerapan Media Kubus Putar Untuk Meningkatkan Kemampuan Mengenal Angka 1-10 Pada Kelompok A TK Syeich Abu Bakar Surabaya. Sebuah penelitian sangat dipengaruhi oleh kualitas instrumenn variabel itu sendiri. Pada sebuah penelitian kualitatif peneliti menjadi sebuah instrument pada sebuah penelitian. 


\section{c. Metode dokumentasi}

Dokumentasi merupakan setiap pernyataan tertulis yang disusun oleh seseorang atau lembaga bagi keperluan pengujian suatu peristiwa. Menurut Moleong, L. J (2010), dokumentasi mendefinisikan bahwa setiap pernyataan tertulis yang disusun oleh lembaga atau seseorang demi keperluan pengujian suatu peristiwa. Menurut (Arikunto, 2010) Di setiap akan melaksanakan metode dokumentasi peneliti menyelidiki benda-benda secara tertulis yaitu, buku-buku, majalah, dokumen, peraturan-peraturan, notulen rapat, catatan harian, dan sebagainya.

\section{Sumber data yang stabil, menunjukkan suatu fakta yang telah berlangsung dan mudah didapat dengan dokumentasi sumber.}

Gambar dan foto yang berupa dokumentasi yang selalu tersedia memiliki tingkat kepercayaan yang tinggi akan kebenaran atau keabsahan dengan data dokumentasi sumber data yang kaya untuk mempercepat proses penelitian adalah dengan dokumentasi. Teknik dokumentasi dalam penelitian ini adalah berupa fotofoto dalam pembelajaran tentang Penerapan Media Kubus Putar Untuk Meningkatkan Kemampuan Mengenal Angka 1-10 Pada Kelompok A TK Syeich Abu Bakar Surabaya.

\section{a. Uji keabsahan}

Menurut Sugiyono (2010.) Uji keabsahan data dalam penelitian kualitatif meliputi uji kredibilitas data, uji transferabiliti, uji depenability, dan uji confirmability. Dalam penelitian ini dipergunaka uji kredibilitas dapat menguji keabsahan data. Uji kredibilitas data yang dilakukan dengan Triangulasi. Sebagai Pengecekan data dari berbagai sumber dengan berbagai cara, dan berbagai waktu arti dari triangulasi data. Ada 3 Triangulasi didalam keabsahan data, yakni triangulasi sumber, Triangulasi metode serta Triangulasi waktu. Dalam penelitian ini, si peneliti memperggunakan Triangulasi sumber, Tringulasi metode serta Tringulasi waktu. Triangulasi sumber ialah akan menguji kredibilitas data yang dilakukan dengan cara mengecek data yang telah diperoleh lewat beberapa sumber. Triangulasi sumber akan dilakukan pada teman-teman di pendidikan, pengurus beserta guru di sanggar pendidikan.

\section{b. Triangulasi metode}

Triangulasi Metode yaitu Peneliti akan menguji dengan cara mengecek data kepada sumber yang sama pada metode yang berbeda, yakni dengan dilakukan observasi, wawancara, dan dokumentas

\section{c. Triangulasi waktu}

Triangulasi waktu adalah pengambilan data yang dilakukan pada pagi hari pada waktu piket bersama disekolah dengan cara wawancara disaat narasumber 
sudah santai, maka besar kemungkinan besar narasumber akan dapat menjawab pertanyaan wawancara dengan lebih rileks dan tegas.

\section{d. Teknik Analisis data}

Analisis data merupakan proses mengatur urutan data mengorganisasikannya ke dalam suatu pola, kategori dan satuan uraian dasar Menurut Afifuddin (2012.). Beberapa analisis data yang digunakan dalam penelitian ini ialah analisis kualitatif deskriptif dengan teknik analisis data penelitian yaitu :

\section{e. Reduksi data}

Penyederhanaan dan abstraksi data yang ada dalam "field note" yang sedemikian hingga kesimpulan dapat dilakukan disebut dengan proses pembukuan.

\section{f. Penarikan kesimpulan}

Setelah analisis data dilakukan, maka peneliti dapat menyimpulkan hasil penelitian yang menjawab rumusan masalah yang ditetapkan oleh peneliti sebelumnya, merupakan penarikan kesimpulan dari proses akhir sebuah penelitian.

\section{HASIL DAN PEMBAHASAN}

\section{Hasil}

Hasil penelitian ialah segala sesuatu yang diperoleh peneliti setelah dilakukan beberapa penelitian dengan memakai prosedur pengumpulan data yang telah terencanakan sebelumnya. Hasil ini berupa ringkasan latar belakang penelitian dari hasil penelitian yang menjadi penekanan utama, sebagaimana dinyatakan kemudian dalam bab ini.

Beberapa temuan yang sesuai dengan pertanyaan peneliti dibahas dalam temuan penelitian ini. Temuan penelitian yang dibahas mencakup gambaran anak secara umum bagaimana perkembangan kognitif anak kelompok A melalui media kubus putar dadu angka di TK Syeich Abu Bakar Surabaya.

Deskriptif kualitatif di penelitian ini menerapkan Triangulasi data yakni berdasarkan dari bukti pengalaman dan pengetahuan. Triangulasi dalam penelitian ini menerapkan wawancara, observasi juga dokumentasi sebagai penilai kemampuan mengenal angka pada peserta didik yang bernama N. Berikut nama informan yang berhasil diwawancarai secara intensif yang ada di TK Syeich Abu Bakar Surabaya:

Tabel 4.1 Data Informan TK Syeich Abu Bakar Surabaya

\begin{tabular}{lc}
\hline No & Initial \\
\hline 1 & $\mathrm{Bu} \mathrm{T}$ \\
\hline 2 & $\mathrm{Bu} \mathrm{L}$ \\
\hline
\end{tabular}


Adapun secara terperinci temuan penelitian di lapangan dapat dijelaskan sebagai berikut :

Bagaimana perkembangan kognitif anak kelompok A melalui media kubus putar dadu angka di TK Syeich Abu Bakar Surabaya. Di dalam Wawancara dan Observasi tentang perkembangan kognitif melalui media kubus putar dadu angka pada anak kelompok A di TK Syeich Abu Bakar Surabaya. Menurut hasil Observasi menyebutkan bahwa perkembangan kognitif melalui media kubus putar dadu angka dengan menunjukkan beberapa angka yang ada di kubus putar dadu angka (CO.1 P.15 B.1-2) yang ditunjuk bu guru dan mengajak menebak angka berapa . Konsep perkembangan anak kelompok A sudah bisa mennyebutkan angka tersebut dengan mengambil benda sesuai dengan angka yang ditebak. (CO.1 P. 16 B.2-3), ( CO.1 P. 18 B.1), (CO.1 P. 19 B. 1), ( CO. 1 P.20 B.1-2).

Tidak itu saja bu guru juga memberikan media kubus putar dadu angka ke salah satu murid bernama M untuk mencoba menghitunya (CO.1 P 22 B. 1-2). Sehingga hasil capaian yang diperoleh dengan media kubus putar dadu angka itu anak- anak sudah mulai bisa menyebutkan angka 1-10 dengan baik.

Selain konsep menyebutkan angka bu guru juga menyiapkan media untuk pembelajaran hari lain (CO.2 P. 22 B. 1-2). Yaitu dengan difokuskan pada menulis angka(CO.2 P. 23 B.1). Sambil membawa kubus angka berapa ini ya coba tebak (CO.1 P.24 B. 1-2), (CO.1 P. 28 B. 1-2),(

CO.2 P. 30 B.1-2). Sehingga semua sudah bisa menyebutkan dan menulis angka 1-10 dengan media kubus putar ini .Dengan cara di putar- putar kubusnya (CO. 2 P.33 B. 1-2).

Sebagaimana hasil wawancara peneliti dengan Kepala Sekolah TK Syeich Abu Bakar Surabaya bahwa "dalam pembelajaran awal anak kelompok A dengan menggunakan media atau APE lain untuk perkembangan kognitif dengan media kubus putar dadu angka sangat tepat sekali dalam mengenal angka 1-10 "(CW.1 P. 6 B.1-2).

Hal serupa juga diungkapkan oleh Wali kelas A1 TK Syeich Abu Bakar Surabaya bahwa konsep pendidikan kognitif dalam mengenalkan angka 1-10 pada anak kelompok A dengan media kubus putar dadu angka ini (CW.2 P. 8 B. 1-3), (CW.2 P. 11 B. 1-3)). Hasil yang dicapai adalah dengan media kubus putar dadu angka belajar mengenal angka 1-10 anak-anak menjadi senang (CW. 2 P. 12 B. 12). Dan menggunakan metode bernyanyi juga untuk mengenalkan angka 1-10 kepada anak kelompok A (CW.2 P.15 B. 1-2).

Upaya pengembangan kognitif anak kelompok A melalui media kubus putar dadu angka di TK Syeich Abu Bakar Surabaya. Menurut hasil observasi di TK Syeich Abu Bakar Surabaya menurut ibu kepala sekolah bahwa upaya pengembangan kognitif anak kelompok A dalam mengenalkan angka adalah dengan dipegang, gurunya mengenalkan media kubus putar dadu angka dengan cara diputar- putar dan dengan bernyanyi. 
Hal senada pun dilakukan oleh bu guru Luluk untuk mengembangkan kognitif anak kelompok A dengan media kubus putar dadu angka Serta mengajak anak-anak bermain tebak angka lalu murid menjawab (CO.1 P. 17 B. 1), (CO.1 P.19 B.1), (CO.1 P. 23 B. 1), (CO.2 P. 25 B.1-2), (CO.2 P. 29 B. 1-2), (.CW.1 P. 10 B. 1-3)

Menurut hasil Wawancara hasil capaian yang dicapai adalah dengan media kubus putar dadu angka ini anak-anak sudah bisa menulis angka sesuai yang ada dikubus putar dadu dengan (CW.1 P. 10 B. 1-3)._Hasil yang dicapai lagi adalah dengan media kubus putar dadu angka belajar mengenal angka 1-10 dengan cara diputar-putar kubus dadu angkanya anak-anak menjadi senang(CW.2 P. 9 B. 1-3), (CW. 2 P. 12. B. 1-2) dan dengan cara bernyanyi juga nyanyian itu melekat untuk anak dan mudah diingat juga bu (CW.2 P. 16 B. 1-2).

\section{PEMBAHASAN}

Perkembangan kognitif anak kelompok A melalui media kubus putar dadu angka ini sangat penting sekali supaya anak-anak dengan mudahnya bisa menyebutkan angka 1-10. Alat Media pembelajaran adalah hal yang penting dalam proses suatu pembalajaran sehingga tercapailah akan tujuan pembelajaran, alat media juga dapat merangsang keinginan anak untuk ikut serta dalam proses pendidikan. Fadillah (2014.) bahwa suatu alat media adalah hal yang tidak dapat dipisahkan dari suatu proses pembelajaran di dalam rangka supaya dapat mencapai suatu tujuan pembelajaran. Dengan adanya sumber pesan maka penerima akan lebih banyak memperoleh informasi. Contoh sumber pesan yang bisa memberikan informasi adalah bahan cetak, televise, computer, film dan lain-lain.

Perkembangan kognitif anak kelompok A melalui media kubus putar dadu angka sangat tepat sekali dari mengenalkan atau menyebutkan angka dengan menunjuk angka 5 lalu anak-anak bisa menyebutkan dan menunjukkan dengan benda dengan jumlah yang sama pula. Selain itu Dengan adanya media kubus putar dadu angka dengan cara diputar-putar sambil berhitung. Selanjutnya dengan menuliskan angka yang ada dikubus putar dadu angka tersebut yaitu angka 1-10. Anak-anak sudah bisa menyebutkan angka 1- 10 dan sudah bisa menulis angka juga.

\section{KESIMPULAN}

Berdasarkan hasil penelitian menunjukkan bahwa melalui penelitian kualitatif perkembangan kognitif anak kelompok A dengan media kubus putar dadu angka membuat anak- anak menjadi bisa menyebutkan dan mengenal bilangan 110 dengan mudah. Dengan bernyanyi pun juga memudahkan anak-anak mengenal angka 1-10. Proses penerapan perkembangan kognitif anak usia dini melalui media kubus putar dadu angka untuk mengenal bilangan di kelompok A TK Syeich Abu Bakar Surabaya bahwa dengan adanya media kubus putar dadu angka ini anak-anak 
sudah mulai bisa mengenal angka/ bilangan 1-10 membuat anak-anak lebih mudah dan bisa mengenal angka. Pengenalan angka / bilangan dari Sejak dini anak-anak sudah sangat totalitas dan antusias dengan terciptanya APE berupa media kubus putar dadu angka ini yang membuat kegiatan pembelajaran berjalan dengan baik.

\section{E. DAFTAR PUSTAKA}

Augusta. (2012). Pengertian Anak Usia Dini. Dari http://infoini.com/pengertian anak usia dini diakses tanggal 17 Februari2012.

Afifuddin. (2012). Metodologi Penelitian Kualitatif. Bandung: Pustaka Setia.

Arikunto, Suharsimi. (2010). Manajemen Penelitian. Jakarta: Rineke Cipta.

Depdiknas. (2007). Pedoman Pembelajaran Permainan Berhitung Permulaan Di Taman Kanak-kanak. Jakarta: Dirjen Dikdasmen.

Dwi Yulianti. (2010). Bermain sambil Belajar Sains di Taman Kanak-kanak. Jakarta: PT Indeks.

Fauziddin, M. (2016). Peningkatan Kemampuan Kerja Sama melalui Kegiatan Kerja Kelompok Pada Anak Kelompok A TK Kartika Salo Kabupaten Kampar. Jurnal Obsesi : Jurnal Pendidikan Anak Usia Dini, 2(1). Indonesia, R. Undang-Undang Nomor 20 Tahun 2003.

Fadillah. (2014). Edutainment pendidikan anak usia dini. Jakarta: Kencana.Jakarta Indeks.

Fitria Uly Khusnaya. (2019). Penggunaan Media Permainan Kartu Angka Dalam Meningkatkan Kemampuan Mengenal Konsep Bilangan Pada Anak Kelompok A Di Tk Islam Terpadu Tazkia Cangkiran Mijen Semarang. Skripsi: Fakultas Ilmu Tarbiyah dan Keguruan Universitas Islam Negeri Walisongo Semarang 2019.

Isjoni. (2010). Model Pembelajaran Anak Usia Dini. Bandung: Alfabeta.

Moleong, L. J. 2010. Metodologi Penelitian Kualitatif. Bandung: PT Remaja Rosdakarya.

Sugiyono. (2014). Metode Penelitian Manajemen. Bandung: Alfabeta.

Sugiyono. (2010). Metodologi Penelitian Administrasi. Jakarta : CV. Alfabeta. 